\title{
THE IDENTITY, DYNAMICS, AND DIFFUSION OF MIS ${ }^{1}$
}

\author{
Tor J. Larsen \\ Norwegian School of Management \\ Oslo, Norway \\ Linda Levine \\ Software Engineering Institute \\ Carnegie Mellon University \\ Pittsburgh, PA U.S.A.
}

\begin{abstract}
This paper examines the key lines of inquiry that have been used in research focused on the identity, dynamics, and diffusion of MIS, as well as the strengths and weaknesses associated with each approach. We present five primary means: (1) citation analysis, (2) classification analysis, including metaanalysis, (3) editorials and opinion pieces. (4) historical surveys of previous work, and (5) forums. We use the term "line of inquiry" since this allows us some latitude in considering dissimilar approaches-methods as well as communication channels. Using examples from the published literature on the status of MIS, we define and illustrate the five approaches. Subsequently, we discuss the strengths and weaknesses of each. Where possible, we extend the discussion to consider the implications of these lines of inquiry for future research.
\end{abstract}

Keywords Management information systems, lines of inquiry, genre

'The authors are listed in alphabetical order but have contributed equally to the article.

Please use the following format when citing this chapter:

Larsen, T. J., and Levine, L., 2007, in IFIP International Federation for Information Processing, Volume 235, Organizational Dynamics of Technology-Based Innovation: Diversifying the Research Agenda, eds. McMaster, T., Wastell, D., Ferneley, E., and DeGross, J. (Boston: Springer), pp. 163-177. 


\section{INTRODUCTION}

No end appears to be in sight for the longstanding discussions on the status of the field of Management Information Systems (MIS) ${ }^{2}$--its identity and its value, with respect to its role as a field, within the university, and in relation to industry practice (Alavi and Carlson 1992; Alter 2003; Avison 2003; Benbasat and Weber 1996; Benbasat and Zmud 2003; Briggs et al. 1999; Carr 2003; Ives et al. 2004; Lyytinen and King 2004; Robey 1996; Orlikowski and Baroudi 1991; Orlikowski and Iacono 2001; Paul 2002; Weber 1987, 2003; Westfall 1999). This self examination reveals two persistent themes. The first focuses on coherence in MIS and in framing questions such as: Does MIS have a core and overarching theory? A cumulative tradition? Are other disciplines referencing MIS? (See Baskerville and Myers 2002; Davis 2000; Pfeffers and Ya 2003; Vessey et al. 2002; Walstrom and Hardgrave 2001.) The second theme revolves around the matter of rigor versus relevance, which is also occasionally expressed as a debate between academic and practical concerns (Benbasat and Zmud 1999; Goles and Hirscheim 2001; Hirschheim and Klein 2003; Nurminen and Eriksson 1999; Robey and Markus 1998). If we are to come to grips with these issues we need to consider the approaches and assumptions that have grown up within our discourse.

Further refinement on the nature of MIS has examined its core and subareas. One approach distinguishes between the internalist view (Westin et al. 1994) and the externalist view (Whitley 1984). The internalist view builds on Kuhn's (1970) notion of a dominant paradigm in the tradition of normal science, which is interspersed with periods of revolution. This dominant paradigm takes the form of an overarching theory, which is subscribed to by a research community. The externalist view treats a discipline as a "complex network of interacting researchers whose ideas may stem from a number of disciplines who therefore form an intellectual community" (Vessey et al. 2002, p. 132).

Benbasat and Zmud (2003) argue that a definition of the IS artifact can serve as the platform for defining appropriate MIS research. Ives et al. (2004) present a strong counterargument. They advocate the field of MIS research is best seen as a "colonial system," where colonies have strong inner ties but loose outer connections. They assert that the glue in MIS is a common interest in information technology and information systems. Similarly, King (1993) describes the discipline of MIS as driven by "a shared interest in a phenomenal event - the rise and consequences of radical improvement in information technology... [and any] attempt to build a long-standing academic field on a phenomenon, especially a revolutionary phenomenon, will fail" (p. 293). As Fitzgerald (2003) aptly observes, "In IS, we stand with our backs to the technology, the computer, the machine or whatever, and look outward towards the world at large" (p. 227).

The purpose of this paper is to provide a preliminary examination of the key lines of inquiry that have been used in research focused on the identity, dynamics, and diffu-

${ }^{2}$ Different labels are used to refer to the field, for example: Information Technology (IT), Information Communication Technology (ICT), Information Systems (IS), Management Information Systems (MIS), and Information Management (IM). Knowledge Management Systems (KMS) is another term that is increasingly in use. Each term has its proponents; however, the terms are often used interchangeably. For the sake of clarity and consistency, we use the term Management Information Systems. 
sion of MIS, as well as the strengths and weaknesses associated with each approach. ${ }^{3}$ We have discerned five primary means: (1) citation analysis, (2) classification analysis, (3) editorials and opinion pieces, (4) historical surveys, and (5) forums. Loosely speaking, each of these represents a type of investigation---or in the case of forum, a place for discussion into the identity and dynamics of MIS. We use the term line of inquiry since this allows us some latitude in considering dissimilar approaches - methods as well as communication channels. Using examples from the published literature on the status of MIS, we define and illustrate the five approaches; subsequently, we discuss the strengths and weaknesses of each. Where possible, we extend the discussion to consider the implications of these lines of inquiry.

\section{LINES OF INQUIRY}

The delineation of the five lines of inquiry has followed from earlier research we conducted on the identity and dynamics of the field of MIS using classification and citation analyses (Larsen and Levine 2005) and our reading of the related literature, as well as online discussion, on the identity crisis in MIS. Throughout our investigations, we have asked: What are the best avenues for examining the field of MIS? And which of these avenues and perspectives are reliant on formal methods (in data collection and analysis) in order to reach conclusions? The five lines of inquiry are addressed in the subsections that follow.

\subsection{Classification Analysis}

Classification studies constitute one of the major approaches to investigating patterns in research (Vessey et al. 2002). One specific instance employs meta-analysis techniques. Meta-analysis uses the common variables and relationships in empirical data to discern general and overarching patterns across different studies. Another classification approach takes a broader perspective and consists of analysis of topic or subject matter. This process involves selecting a topic and reviewing many journals and conference proceedings in order to find evidence of patterns, trends, similarities, and differences. The articles considered in a topical analysis may be either quantitative or qualitative and need not adhere to any common method.

Vessey et al. (2002) perform a classification study pertaining to diversity in the IS field. They employ five dimensions of diversity: reference discipline, level of analysis,

${ }^{3}$ A point about the identity and dynamics of MIS and the role of a paradigm is in order. We considered the analytical approach that Pfeffer (1993) describes for verifying the existence of a disciplinary paradigm. Pfeffer forwards 14 variables that should be represented when a paradigm exists, including funding levels of departments, connection between productivity and pay, department-head turnover or average tenure, and cross-citation practices among fields. The general sentiment is that MIS does not have a paradigm. Hence, we concluded that the most rewarding approach would be to focus on key lines of inquiry - the means by which research issues, constructs, and variables have been investigated and communicated. 
topic, research approach, and method. These dimensions are then individually refined into subcategories. They identify five top IS journals and code their articles, from 1995 through 1999, according to these dimensions and subcategories. This study approach is based on classification by inspection.

A more formal and rigorous instance of classification analysis is co-word analysis. Monarch (2000) surveys the history of research on co-word analysis. He describes the technique as revealing

patterns and trends in technical discourse by measuring the association strengths of terms representative of relevant publications....A main tenet of co-word analysis is that the identified patterns of representative term associations are maps of the conceptual structure or knowledge network of a technical field and that a series of such maps produces a fairly detailed representation of the subject matter of a discipline.... Co-word analysis enables the structuring of data at various levels of analysis: (1) as networks of links and nodes (nodes hold terms); links connect nodes, thereby forming networks; (2) as distributions of interacting networks; and (3) as transformation of networks over time periods (Monarch 2000, pp. 5-6).

A word about the distinction between co-word analysis and co-citation analysis is in order. Whereas co-citation analysis maps "the structure of a research field through pairs of documents that are jointly cited...co-word analysis deals directly with sets of terms shared by documents... and maps the pertinent literature directly from the interactions of key terms instead of from the interactions of citations" (Monarch 2000, pp.5-6, emphasis added; see also Small 1973). Co-word analysis shows links on the basis of content.

\subsection{Citation Analysis}

Citation analysis involves several types of study, including direct citation, co-citation analysis, and bibliographic coupling. Small (1973) observes that direct citation-the citing of an earlier document by a new document -and bibliographic coupling have received considerable attention. Bibliographic coupling links source documents. However, in measuring co-citation strength, researchers measure the degree of relationship or association between papers as perceived by the population of citing authors. Furthermore, because of this dependence on the citing authors, these patterns can change over time, just as vocabulary co-occurrences can change as subject fields evolve (Small 1973, p. 265). Small observes that many information scientists focus attention on the operation of document retrieval systems serving scientists in various fields. The scientists who are served by these systems comprise an invisible college (Crane 1972) networks of scientists "in frequent communication with one another and involved with highly specialized subject matters" (Small 1980, p. 183).

Culnan and Swanson (1986) use citation analysis to measure how MIS is evolving as a standalone discipline separate from its foundation disciplines of computer science, management science, and organization behavior. Their analysis studied 271 articles across seven outlets (six journals and one conference proceedings) over the period of 
1980 through 1984. They concluded that (1) MIS remains less established than its foundation disciplines, (2) MIS is growing and maturing, in terms of output and cited references, and (3) there is no consensus as to a body of work integral to the field. Culnan (1986, 1987) examines trends in MIS research, and observes that MIS management issues have emerged as a subfield. Moreover, the traditional emphasis on technology and technical issues has been displaced by a strong organizational and managerial focus. Culnan considers the intellectual structure of MIS research, and based on cocitation analysis, she identifies five invisible colleges (or informal clusters of research activity): foundations, psychological approaches to MIS design and use, MIS management, organizational approaches to MIS design and use, and curriculum.

Citation analysis remains a popular means to investigation of the nature of the discipline. For example, Katerattanakul and Hong (2003) assess the quality of MIS Quarterly and compare this assessment to other journals of other disciplines. They conclude that MIS Quarterly ranks favorably in comparison with specialty journals and respectably among general journals (of specific disciplines).

\subsection{Issues, Opinions, and Commentaries}

The development of a field requires ongoing debate on its future direction and underlying assumptions. Sometimes this takes the form of thematic editorials. Issues, opinions, commentaries, and thematic editorials are usually based upon expertise and experience, rather than on empirical inquiry. Those who contribute to this discourse often play central roles in the field, as senior editors of leading journals, and as well-respected members of the research community. They are recognized for their valuable contributions made over the years. Some journals explicitly make room for ongoing discussion and occasionally or regularly accept papers falling under an issues and opinions category (e.g., MIS Quarterly, Information Systems Research, Management Science, and European Journal of Information Systems). Each journal takes a slightly different tact, so that a variety of labels are used for this purpose: issues and opinions, research commentaries, management insight, and editor's view.

An excellent example of an issues and opinions contribution on the development of the field of IS is Baskerville and Myers (2002). They propose that MIS has matured and now serves as a bona fide source of reference for researchers in other scientific fields. They declare (Table 1, p. 4) that research contributions in MIS include five bodies of knowledge, each with concepts, theories, processes, and applications; and typically, these research contributions are published in MIS journals. Baskerville and Myers posit a new reality where information technology and systems have become ubiquitous in the industrialized world and where many fields have developed a research interest in information and communications technology. By extension, they argue that rather "than conceptualizing the process of knowledge creation as unidirectional (being part of a food chain with IS at one end), we can conceptualize this process as multidirectional. IS scholars along with scholars in other fields can be seen as part of many knowledge creation networks throughout the world" (pp. 5-7). Baskerville and Myers' issue and opinion piece stimulated further dialogue, making it part of an ongoing conversation about the identity of MIS (Avison 2003; Katerattanakul et al. 2006; Kock and Davison 2003; Larsen and Levine 2006; Nambisan 2003; Vessey et al. 2005). 
Another influential example of a research commentary is found in Orlikowski and Iacono's (2001) work on theorizing the IT artifact. They draw upon a review of articles published in Information Systems Research, from 1992 through 2002, and argue that the field has not deeply engaged its core subject matter--the information technology artifact. They maintain that IS researchers have largely been preoccupied with context, discrete processing capabilities, and dependent variables. As a result, researchers have neglected the IT artifact itself, or taken it to be unproblematic. Orlikowski and Iacono propose that IS researchers begin to theorize about the IT artifact. Their commentary succeeded in opening a dialogue on the nature of the IT artifact (Benbasat and Zmud 2003; Ives et al. 2004; Myers 2002).

A final note about issues and opinions is in order: these contributions can vary substantially. For example, robust and extensive discussions of this type on the nature of a discipline can extend into theory development and be expressed in the form of a monograph or book (Checkland and Holwell 1998; Currie and Galliers 1999; Zmud 2000).

\subsection{Historical Surveys}

Historical surveys are conducted at various levels, including high-level explorations of MIS, as well as lower-level exploration of subareas within MIS. In addition, more extensive treatments of the history of technology are presented in monographs and books (Kurzweil 1999; Stork 1997). These histories of technology are beyond the scope of the present study.

An example of high-level exploration is found in Beniger (1986). According to Beniger, the degree of control a society can exert over life, production, people, money, and information has drastically changed. He describes how four levels of control have developed over time: life, culture, bureaucracy, and technology. In Beniger's view, the control revolution explains why modern economies have become distinctively more purposive systems. A major purpose of this revolution is to bring under control (of managers and politicians alike) society's ever faster material processing systems.

Davis (2000) examines the conceptual foundations of MIS, focusing on the set of high- level concepts and propositions that explain the rationale for structures, scheduling and accomplishment of tasks, and performance of activities. He identifies three approaches to the formulation of conceptual foundations, based on (1) intersection - where ideas are taken from any field, (2) core - where the focus is on distinct ideas within MIS, and (3) evolution-combining the notions of intersection and core.

Good examples of historical survey in a subarea-group support systems (GSS)are found in descriptive evaluations by Fjermestad and Hiltz $(1998,2000)$. Their article published in 1998 addresses methodologies employed and results obtained in experimental GSS research. This systematization covers the period 1972 through 1998 and reports on approximately 200 controlled experiments published in 230 articles. The analysis is divided in two parts. Part I covers contextual and intervening factors. Part II presents an overview, synthesizing 1,582 hypotheses resulting from pairings of independent and dependent variables. In the article published in 2000 , the authors perform a descriptive evaluation of 54 case and field studies from 79 published papers, spanning the years 1980 through 2000 . These evaluations are purely descriptive and do not offer any conclusions. 
One dimension of historical critique that is largely missing in the literature on the identity of MIS is reflection on the accuracy and veracity of predictions that have been made with respect to information systems. An exception is found on organizational structure and the role of middle managers. In 1958, Leavitt and Whisler anticipated that in the 1980s the use of mathematical programming, operations research, and simulation of higher-order thinking through computer programs would become part of the manager's daily routine. Use of the computer would alter managerial work and shrink the middle management layer. For decades these changes eluded us (Hunt and Newell 1971).

More recent developments confirm some of Leavitt and Whisler's predictions (Applegate et al. 1988). Today, the middle management population is reduced. Newly introduced management control systems, executive information systems, telecommunication networks, e-mail, topic-specific global databases, office automation, standard packages, data warehouses, and the multi-media web are just some of the IT services that have facilitated these changes. Leavitt and Whisler speculated that modern computer use would lead to centralization. Today, however, we see centralization, decentralization, and outsourcing occurring simultaneously. And, as the role of middle managers shifts from control (over the execution of planned activities) to feeding organizational innovation processes, the need for managers may climb again (Dutton and Ashford 1993).

\subsection{Forums}

Dialogue on the identity and dynamics of the discipline also occurs through forums where members of the community "talk" with one another. These forums include face to face conferences and virtual mediums such as listservs, discussion groups, and blogs. Virtual conferences are a hybrid. The degree of formality in forums varies. Conference presentations are the most formal; panels are somewhat formal; and listservs, discussion groups, and blogs are the most informal.

For example, at a recent conference, a panel discussion focused on the discipline of MIS (Larsen and Levine 2006). The panelists considered myths and taboos in the history of the field, interdisciplinary identities, intradisciplinary perspectives, and empirics on coherence and change.

Virtually, a 2006 dialogue on the ISWorld listserv focused on the search for a "bumper sticker" for MIS. The post spurred a flurry of roughly 140 responses. Subscribers who replied emphasized a wide range of issues, characteristics, and audiences for bumper stickers. Some focused on the need for a short and catchy message; others discussed the meaning of the field, and real differences between information systems and information technology.

Such debates on the identity of MIS are common, ongoing, and almost recursiveindeed, no end appears to be in sight for the now familiar, longstanding discussions on the status of the field.

\subsection{Summary}

In summary, Table 1 presents each line of inquiry and its major facets. 
Table 1. Lines of Inquiry and Their Major Facets

\begin{tabular}{|c|c|c|c|c|}
\hline $\begin{array}{l}\text { Line of } \\
\text { Inquiry }\end{array}$ & Definition/Purpose & Dataset & $\begin{array}{c}\text { Method \& } \\
\text { Tools } \\
\end{array}$ & Output \\
\hline Classification & $\begin{array}{l}\text { Classifies/codes cate- } \\
\text { gories of interest, } \\
\text { typically topic variable, } \\
\text { and research method. } \\
\text { Includes co-word } \\
\text { analysis and meta } \\
\text { analysis. }\end{array}$ & $\begin{array}{l}\text { Texts or key- } \\
\text { words in } \\
\text { articles, con- } \\
\text { ference pro- } \\
\text { ceedings, etc. }\end{array}$ & $\begin{array}{l}\text { Can be per- } \\
\text { formed manu- } \\
\text { ally or via } \\
\text { automated } \\
\text { tools }\end{array}$ & $\begin{array}{l}\text { Tables of codes, } \\
\text { topic variables, } \\
\text { and research } \\
\text { methods } \\
\text { Co-word } \\
\text { analysis: } \\
\text { clusters of terms } \\
\text { Meta analysis: } \\
\text { tables and } \\
\text { graphs }\end{array}$ \\
\hline Citation & $\begin{array}{l}\text { Establishes relations } \\
\text { among documents and } \\
\text { includes (1) direct cita- } \\
\text { tion-citing of earlier } \\
\text { document by new docu- } \\
\text { ment, (2) bibliographic } \\
\text { coupling: sharing of } \\
\text { one or more references } \\
\text { by two documents. } \\
\end{array}$ & $\begin{array}{l}\text { Publications } \\
\text { (articles, con- } \\
\text { ference } \\
\text { proceedings) }\end{array}$ & As above & $\begin{array}{l}\text { Relationships } \\
\text { among docu- } \\
\text { ments (timeline, } \\
\text { list, or tree } \\
\text { diagram) } \\
\text { Co-citation } \\
\text { network: author } \\
\text { or issue clusters }\end{array}$ \\
\hline $\begin{array}{l}\text { Historical } \\
\text { Surveys }\end{array}$ & $\begin{array}{l}\text { Allows reflection on the } \\
\text { past and predictions for } \\
\text { the future; presents pat- } \\
\text { terns and trends. } \\
\text { Recounts discrete } \\
\text { elements (events and } \\
\text { developments) in a } \\
\text { larger context. }\end{array}$ & $\begin{array}{l}\text { Events, } \\
\text { records, } \\
\text { documents, } \\
\text { artifacts, } \\
\text { interviews }\end{array}$ & $\begin{array}{l}\text { Direct account } \\
\text { or recording, } \\
\text { statistical or } \\
\text { interpretative } \\
\text { analysis }\end{array}$ & $\begin{array}{l}\text { Survey, } \\
\text { account, or } \\
\text { narrative as } \\
\text { documented in } \\
\text { mixed media }\end{array}$ \\
\hline $\begin{array}{l}\text { Issues, } \\
\text { Opinions, and } \\
\text { Commentaries } \\
\end{array}$ & $\begin{array}{l}\text { Wide ranging, } \\
\text { subjective. }\end{array}$ & \begin{tabular}{|l|} 
Author's \\
experiences \\
and reflections
\end{tabular} & $\begin{array}{l}\text { Interpretive } \\
\text { and analytical }\end{array}$ & $\begin{array}{l}\text { Essay or } \\
\text { editorial opinion }\end{array}$ \\
\hline Forums & $\begin{array}{l}\text { Includes face-to-face } \\
\text { and virtual interactions: } \\
\text { listservs, discussion } \\
\text { groups, Wikis, blogs. }\end{array}$ & $\begin{array}{l}\text { Authors' } \\
\text { conducted } \\
\text { research, } \\
\text { experiences } \\
\text { and reflections }\end{array}$ & $\begin{array}{l}\text { Interpretive, } \\
\text { analytical, } \\
\text { conversational }\end{array}$ & $\begin{array}{l}\text { Conference pre- } \\
\text { sentations and } \\
\text { panels; infor- } \\
\text { mal communi- } \\
\text { cations }\end{array}$ \\
\hline
\end{tabular}

\section{DISCUSSION OF STRENGTHS AND WEAKNESSES}

In considering these lines of inquiry into the identity, dynamics, and diffusion of MIS-(1) classification analysis, (2) citation analysis, (3) issues, opinions and commentaries, (4) historical surveys, and (5) forums-we were obliged to ask a number of questions: What limitations are inherent in each line of inquiry? What are the strengths and weaknesses associated with each? How does each contribute to the dialogue on the identity and dynamics of the discipline? 


\subsection{Classification Analysis}

Classification analysis has three key strengths. First, classification analysis (including meta-analysis) focuses on identifying phenomena that are shared across research results and synthesizes these findings in a coherent manner. Second, it contributes to a cumulative research tradition, which involves building upon other researchers' theories and replicating or extending those theories and analyses. Third, meta-analysis requires identification of specific, precise variables that are operationalized across studies. Thus, classification analysis allows for precision in discussions about the field of MIS.

However, some weaknesses apply to the pursuit of precision. The nature of classification analysis, as a method, is narrow; and its focus on similarities carries the risk that one may overlook differences in the richness of the real world. Similarly, a preoccupation with rigor may dominate and become a goal in its own right, so that the researcher loses sight of what is really meaningful. This poses a dilemma: the objective of a classification study is to classify, and so the results may be too narrow or they may be precise and crystal clear.

To date, classification analysis has been employed to a limited extent but use of this method may take off given increased availability of automated support (e.g., tools and databases)

\subsection{Citation Analysis}

Citation analysis builds upon the assumption that "the document is viewed as symbolic of the idea expressed in the text" (Small 1978, p. 327). The method of citation analysis provides insight into groupings or clusters of topics and authors in a manner that is not otherwise visible. Citation analysis is a good means to discern the role of reference disciplines with respect to MIS and its subfields.

Like classification methods, citation analysis is largely objective, factual, and based on data. However, interpretation is required in framing the research questions and facts, and in analyzing and communicating the results. This method offers a single, powerful lens on the dynamics of the discipline, but is also a limited, simplified, and partial view. By itself, it is insufficient to characterize the workings of the discipline - as it doesn't come to grips with the substantive content that makes up the datasets. The same may be said for classification analysis.

To date, citation analysis has been employed to a limited extent since this research is difficult and cumbersome to perform. The advent of tools and electronic databases offers dramatic opportunity for conducting this type of research.

\subsection{Historical Surveys}

Historical surveys allow for flexibility and can be performed in conjunction with other methods to yield quantitative results (e.g., Fjermestad and Hiltz 1998, 2000). Through reflection, historical surveys make us aware of our roots and sources, and can serve as a path to understanding the present course and directions for the future. A historical approach requires a long view. While events and phenomena invite reexamination, those who take a long view are less likely to reinvent the wheel. 
Histories can be deceptive and give the appearance of objectivity by adopting a style that reports the "facts." However, we know that facts are always framed by an author's perspective and intent. Sometimes there is a slippery slope between an historical account and political discourse, which is closely tied to personal interests. History is written by the victor. In a related manner, histories can employ a theme or metaphor that is distorted or wrong-headed. For example, in Beniger's view, the control revolution explains why modern economies have become distinctively more purposive systems. But what if there is a better theory that explains power relations than this matter of control?

\subsection{Issues, Opinions, and Commentaries}

These treatments are wide ranging, impressionistic, subjective, innovative, and are not constrained by expectations of rigor or research methods. These contributions can open up a dialogue on future promising research activities or identify dead avenues. Issues, opinions, and commentaries may take the form of a colloquy - a conversation occurring within a print journal or across several journals (see discussion of the IS artifact in section 2.3). Since these contributions may lack data or direct evidence, they rarely build upon one another in an empirical manner, as part of a cumulative research tradition.

Conversations are an enigmatic phenomenon. Oftentimes, we debate the same issues over and over again, and it may feel as if we're thrashing. But, communities need to be nurtured in many strange ways - maturation is nonlinear. Progress and growth are a slow business. Discussion topics can be revisited for many reasons, including political refocusing, incomplete understanding, knowledge loss, and emergent information.

\subsection{Forums}

Forums allow for the push and pull of ideas. Face to face interactions, listservs, discussion groups, Wikis, blogs, and web-based forums are all push and pull, depending upon the intent of the speaker. Such forums support debate and information sharing and create interest and engagement. Virtual forums bring people together who would otherwise never be in contact.

The structure of discussion may repeat itself in conversational streams over time, so that the community doesn't appear to be learning even though its individual members are gaining an understanding of discrete topics. This is probably the result of people "coming and going." Virtual forums are also subject to "flaming" due to the unique nature of the medium, where it is easy to respond quickly and rashly.

Face-to-face conferences and panels offer a platform for focused exploration. However, these interactions can also fail to support community building and learning across events and over time.

\section{IMPLICATIONS AND CONCLUSION}

There is a long history of research on knowledge creation and diffusion, paradigms and scientific revolutions, as well as disciplines and field theory. For example, Crane (1972, p. 1) writes 
In the last two decades, dramatic increase in the scope and volume of scientific research have occurred, as may be illustrated by the fact that the amount of scientific literature is doubling approximately every ten years (De Solla Price 1963). For the scientist who needs to locate particular items of scientific information and for the documentation specialist who must make them readily available, the organization and management of this huge and expanding store of information is a serious problem. Increasingly radical solutions are being proposed. For example, some experts would like to scrap scientific journals and distribute their contents piecemeal. Information retrieval and delivery systems are being developed to enable scientists to locate information quickly and effectively.

But in sharp contrast with the attention being paid to how knowledge is stored, distributed, and used, relatively little attention has been paid to why and how knowledge grows.

Thirty-five years later, we are still grappling with the problem of why and how knowledge grows. The focus of this article is more specific in that we are concerned with the body of knowledge of MIS and its identity, dynamics, and diffusion. Our charge, as professionals, is made even more challenging since in some universities the existence of MIS as a separate and distinct organizational unit is in question.

What have we learned from this preliminary investigation? We have confirmed that the identity and dynamics of MIS are of concern across these five lines of inquiry. Each line tackles this subject in its own manner, and in keeping with the essential properties and conventions (unspoken rules, values, and norms) of that approach. By necessity, greater reliance on structure and data are associated with the classification and citation studies - these studies could not be performed otherwise. On the more flexible side, issues, opinions, and commentaries are frequently a catalyst for debate about MIS and its purpose and core.

Each approach allows a lens on the field, where the plurality of perspectives constitutes a total view. Together, the lines of inquiry compose a Cubist painting. This composite is the closest we can get to a complete picture of the field. The present investigation has allowed us to think consciously about our repertoire - recognizing the various contributions derived from each approach, finally to realize that understanding comes through the amalgamation of the perspectives. At the start, intellectually, we knew this to be the case but we had not seen it expressed in specific and concrete terms.

Moreover, the contributions within the five lines of inquiry build a robust dialogue across the field of MIS, where diversity enhances the communications and interactions of the players. In a rich field, many flowers bloom. A single mode of operation and a unified view can lend focus, but can also become a straitjacket. Rather, we (the authors) are inclined to plurality and diversity even though this brings inevitable complications. While the field of MIS struggles with its identity and desire for a core, we see clear signs of an engaged and vibrant community.

There is a significant need for high quality classification and citation analysis studies. Today, there is simply too little of this. In the longer term, such studies would influence the formulation of future research activities. In addition, high-level analysis across deductive statistical approaches (as in meta-analyses) and inductive approaches (as in co-word analysis), will allow us to ferret out messages that otherwise cannot be detected. More historical surveys are needed to aid synthesis and direction for the future. 
Greater emphasis on reflection is called for through commentaries and substantial editorials that do more than present mundane summaries of the articles included in a journal issue. We must target and encourage discussion, debate, and colloquy. More "wild goose chase" forum debates, such as the recent one on bumper stickers, spur lively discussion. This is not intended to replace the need for extended inquiry on key issues (What is information? What is an information system? What is the core of the field?). Where possible, it would be productive to introduce mechanisms that propel discussion into action. This might occur through sustained use of working groups, special interest groups, and societies. If we are to successfully wrestle with the challenges of our discipline, we must envision ourselves contributing to a network, which mirrors the vision and capabilities of the information systems that we study.

Future research into lines of inquiry, associated methods, and genre systems (Yates and Orlikowski 2002) will help to surface the conventions of each approach-so that biases and underlying assumptions may be clearly exposed. Such awareness will enable better critique and better evaluations of the claims and evidence employed in each approach.

If the "medium is the message," as McLuhan and Lapham (1994) state, future research might query the quality of the academic field of MIS in terms of the relative use of the five lines of inquiry. This would require data on how much each line of inquiry is used to convey MIS scholarship and a comparative rating of the lines of inquiry. By extension, one might pursue a contingency framework asserting that messages conveyed through the "right" medium have greater impact or influence than when those messages are conveyed through the "wrong" medium. Since all elements of this argument are subject to interpretation, this is particularly difficult terrain.

\section{References}

Alavi, M., and Carlson, P. "A Review of MIS Research and Disciplinary Development," Journal of Management Information Systems (8:4), Spring 1992, pp. 45-62.

Alter, S. "18 Reasons Why IT-Reliant Work Systems Should Replace 'The IT Artifact' as the Core Subject Matter of the IS Field," Communications of the AIS (12), 2003, pp. 365-394.

Applegate, L. M., Cash, Jr., J. I., and Mills, Q. "Information Technology and Tomorrow's Manager," Harvard Business Review, November-December 1988, pp. 128-136.

Avison, D. E. "Is IS an Intellectual Subject?," European Journal of Information Systems (12:3), September 2003, pp. 229-230.

Baskerville, R. L., and Meyers, M. D. "Information Systems as a Reference Discipline," MIS Quarterly (26:1), March 2002, pp. 1-14.

Benbasat, I., and Weber, R. "Research Commentary: Rethinking 'Diversity' in Information Systems Research," Information Systems Research (7:4), December 1996, pp. 389-399.

Benbasat. I., and Zmud, R. W. "Empirical Research in Information Systems: The Practice of Relevance," MIS Quarterly, 23(1), March 1999, pp. 3-16.

Benbasat, I., and Zmud, R. W. "The Identity Crisis Within the IS Discipline: Defining and Communicating the Discipline's Core Properties," MIS Quarterly (27:2), June 2003, pp. 183-194.

Beniger, J. R. The Control Revolution: Technological and Economic Origins of the Information Society, Cambridge, MA: Harvard University Press, 1986.

Briggs, R. O., Nunamaker Jr., J. F., and Sprague, R. "Exploring the Outlands of the MIS Discipline," Journal of Management Information Systems (16:3), Winter 1999-2000, pp. 5-9. 
Carr, N. G. "IT Doesn't Matter," Harvard Business Review (81:5), May 2003, pp. 41-49.

Checkland, P., and Holwell, S. Information, Systems and Information Systems: Making Sense of the Field, Chichester, UK: John Wiley \& Sons, 1998.

Crane, D. Invisible Colleges: Diffusion of Knowledge in Scientific Communities. Chicago, IL: University of Chicago Press, 1972.

Culnan, M. "The Intellectual Development of Management Information Systems, 1972-1982: A Co-Citation Analysis," Management Science (32:2), 1986, pp. 156-172.

Culnan, M. "Mapping the Intellectual Structure of MIS, 1980-1985: A Co-Citation Analysis," MIS Quarterly (11:3), September 1987, pp. 340-352.

Culnan, M. J., and Swanson, E. B. "Research in Management Information Systems, 1980-1984: Points of Work and Reference," MIS Quarterly (10:3), September 1986, pp. 289-302.

Currie, W., and Galliers, B. (eds.). Rethinking Management Information Systems: An Interdisciplinary Perspective, Oxford, UK: Oxford University Press, 1999.

Davis, G. B. "Information Systems Conceptual Foundations: Looking Backward and Forward," in R. Baskerville, J. Stage, and J. DeGross (eds.), The Social and Organizational Perspective on Research and Practice in Information Technology, Boston: Kluwer Academic Publishers, 2000, pp. 61-82.

De Solla Price, D. Little Science, Big Science, New York: Columbia University Press, 1963.

Dutton, J. E., and Ashford, S. J. "Selling Issues to Top Management," Academy of Management Review (18:3), 1993, pp. 231-244.

Fitzgerald, G. "Information Systems: A Subject with a Particular Perspective, No More, No Less (Response to Paul 2002)," European Journal of Information Systems (12), 2003, pp. 225-228.

Fjermestad, J., and Hiltz, S. R. "An Assessment of Group Support Systems Experimental Research: Methodology and Results," Journal of Management Information Systems (15:3), Winter 1998-1999, pp. 7-149.

Fjermestad, J., and Hiltz, S. R. "Group Support Systems: A Descriptive Evaluation of Case and Field Studies," Journal of Management Information Systems, (17:3), Winter 2000-2001, pp. $115-159$.

Goles, T., and Hirschheim, R. "The Paradigm is Dead, the Paradigm is Dead...Long Live the Paradigm: The Legacy of Burell and Morgan," Omega 28(3), 2000, pp. 249-268.

Hirschheim, R., and Klein, H. K. "Crisis in the IS Field?," Journal of the Association for Information Systems (4:5), 2003, pp. 237-293.

Hunt, J. G. and Newell, P. F. "Management in the 1980's Revisited," Personnel Journal (50:1), January 1971 , pp. 35-43, 71 .

Ives, B., Parks, M. S., Porra, J., and Silva, L. "Phylogeny and Power in the IS Domain: A Response to Benbasat and Zmud's Call for Returning to the IT Artifact," Journal of the Association for Information Systems (5:3), March 2004, pp.108-124.

Katerattanakul, P., Han, B., and Rea, A. "Is Information Systems a Reference Discipline?" Communications of the ACM (49:5), May 2006, pp. 114-118.

Katerattanakul, P., and Hong, S. "Quality and Knowledge Contribution of MISQ: A Citation Analysis," Communications of the Association for Information Systems (11), 2003, pp. 271-288.

King, J. L. "Editorial Notes," Information Systems Research (4:4), December 1993, pp. 291-298.

Kock, N., and Davison, R. "Dealing with Plagiarism in the Information Systems Research Community: A Look at Factors That Drive Plagiarism and Ways to Address Them," MIS Quarterly (27:4), December 2003, pp. 511-532.

Kuhn, T. S. The Structure of Scientific Revolution ( $2^{\text {nd }}$ ed.), Chicago, IL: The University of Chicago Press, 1970.

Kurtzweil, R. The Age of Spiritual Machines: When Computers Exceed Human Intelligence, New York: Penguin Books, 1999.

Larsen, T. J., and Levine, L. with Land, F., Myers, M. D., and Zmud, R. "The Identity and Dynamics of MIS," panel presentation in D. Avison, S. Elliot, J. Krogstie, and J. Pries-Heje (eds.), 
The Past and Future of Information Systems: $1976-2006$ and Beyond, IFIP $19^{\text {th }}$ World Computer Congress, and TC8 Information System Stream, New York: Springer Science and Business Media, 2006, pp. 101-106.

Larsen, T. J., and Levine, L. "Searching for MIS: Coherence and Change in the Discipline," Information Systems Journal (15), 2005, pp. 357-381.

Leavitt, H. J. and Whisler, T. L. "Management in the 1980's," Harvard Business Review (36:6), November-December 1958, pp. 41-48.

Lyytinen, K., and King, J. L. "Nothing at the Center? Academic Legitimacy in the Information Systems Field," Journal of the Association for Information Systems (5:6), June 2004, pp. 220-246.

McLuhan, M., and Lapham, L. H. Understanding Media: The Extensions of Man, Boston, MA.: The MIT Press, 1994.

Monarch, I. "Information Science and Information Systems: Converging or Diverging?," in A. Kublik (ed.), Proceedings of the $28^{\text {th }}$ Annual Conference of the Canadian Association for Information: Dimensions of a Global Information Science, 2000 (available online at http:// www.slis.ualberta.ca/cais2000/monarch.htm).

Myers, M. D. "The IS Core-VIII. Defining the Core Properties of the IS Discipline: Not Yet, Not Now," Communications of the Association for Information Systems (12), 2002, pp. 582-587.

Nambisan, S. "Information Systems as a Reference Discipline for New Product Development," MIS Quarterly (27:1), March 2003, pp. 1-18.

Nurminen, M. I., and Eriksson, I. V. "Information Systems Research: The 'Infurgic' Perspective," International Journal of Information Management (19), 1999, pp. 87-94.

Orlikowski, W. J., and Baroudi, J. J. "Studying Information Technology in Organizations: Research Approaches and Assumptions," Information Systems Research (2:1), March 1991, pp. $1-28$.

Orlikowski, W. J., and Iacono, C. S. "Research Commentary: Desperately Seeking the 'IT' in IT Research-A Call to Theorizing the IT Artifact," Information Systems Research (12:2), June 2001, pp. 121-134.

Paul, R. J. "Is Information Systems an Intellectual Subject?," European Journal of Information Systems (11), 2002, pp.174-177.

Pfeffer, J. "Barriers to the Advance of Organizational Science: Paradigm Development as a Dependent Variable," Academy of Management Review (18:4), 1993, pp. 599-620.

Pfeffers, K., and Ya, T. "Identifying and Evaluating the Universe of Outlets for Information Systems Research: Ranking the Journals," Journal of Information Technology Theory and Application (5:1), 2003, pp. 63-84.

Robey, D. "Research Commentary: Diversity in Information Systems Research: Threat, Promise, and Responsibility," Information Systems Research (7:4), December 1996, pp. 400-408.

Robey, D., and Markus, M. L. "Beyond Rigor and Relevance: Producing Consumable Research about Information Systems," Information Resources Management Journal (11:1), Winter 1998, pp. 7-15.

Small, H. "Cited Documents as Concept Symbols," Social Studies of Science (8:3), August 1978, pp. 327-340.

Small, H. "Co-citation Context Analysis and the Structure of Paradigms," The Journal of Documentation (36:3), 1980, pp. 183-196.

Small, H. "Co-citation in the Scientific Literature: A New Measure of the Relationship Between Two Documents," Journal of the American Society for Information Science, July-August 1973, pp. 265-269.

Stork, D. G. HAL's Legacy: 2001's Computer as Dream and Reality, Cambridge, MA: The MIT Press, 1997. 
Vessey, I., Ramesh, V., and Glass, R. L. "Research in Information Systems: An Empirical Study of Diversity in the Discipline and ts Journals," Journal of Management Information Systems (19:2), Fall 2002, pp. 129-174.

Vessey, I., Ramesh, V., and Glass, R. L. "A Unified Classification System for Research in the Computing Disciplines," Information \& Software Technology (47:4), March 2005, pp. 245-255.

Walstom, K. A., and Hardgrave, B. C. "Forums for Information Systems Scholars: III," Information \& Management (39), 2001, pp. 117-124.

Weber, R. "Toward a Theory of Artifacts: A Paradigmatic Base for Information Systems Research," Journal of Information Systems (1:2), Spring 1987, pp. 3-19.

Weber, R. "Still Desperately Seeking the IT Artifact," MIS Quarterly (27:2), June 2003, pp. iii-xi.

Westfall, R. D. "An IS Research Relevance Manifesto," Communications of the Association for Information Systems (2:paper\#I4), September 1999 (available online at http://cais.aisnet.org/ articles/2-14/article.htm).

Westin, S. M., Roy, M., and Kim, C. K. "Cross-Fertilization of Knowledge: The Case of MIS and its Reference Disciplines," Information Resources Management Journal (7:2), 1994, pp. 24-34.

Whitley, R. The Intellectual and Social Organization of the Sciences, Oxford, England: Clarendon Press, 1984.

Yates, J., and Orlikowski, W. "Genre Systems: Structuring Interaction Through Communicative Norms," The Journal of Business Communication (39:1), January 2002, pp. 13-35.

Zmud, R. W. (ed.). Framing the Domains of IT Management: Projecting the Future Through the Past, Cincinnati, OH: Pinnaflex Educational Resources, Inc., 2000.

\section{Acknowledgement}

The authors would like to thank Andrew Van de Ven for his helpful suggestions on an earlier version of this article.

\section{About the Authors}

Tor J. Larsen earned his Ph.D from the University of Minnesota in 1989. He has served as associate editor for MIS Quarterly and is currently a member of the editorial board for Information \& Management. Tor's publications include articles in Information \& Management, Journal of $M I S$, and Information Systems Journal. His research interests are in the areas of innovation, outcome, and research philosophy. Tor can be reached by e-mail at Tor.J.Larsen@bi.no.

Linda Levine is a senior member of the technical staff at Carnegie Mellon University's Software Engineering Institute. She is a member of the IEEE Computer Society, Association for Information Systems, National Communication Association, and cofounder and chair of IFIP Working Group 8.6 on Diffusion, Transfer and Implementation of Information Technology. Linda can be reached by e-mail at LL(o) sei.cmu.edu. 